\title{
Formulación de dieta artificial para la crianza de Spodoptera frugiperda utilizando insumos de la región de San Martín
}

Formulation of artificial diets for the raising of Spodoptera frugiperda using inputs from the San Martín region

Cerna-Mendoza, Agustín ${ }^{1[0000-0002-4827-9966]}$; Coronado, Manuel F. ${ }^{1[0000-}$ 0002-3263-6869]; Doria-Bolaños, Manuel 1[0000-0001-9202-973X]; García-

Gonzales, Patricia ${ }^{1[0000-0003-3490-1977]}$ y Fachin-Ruiz, Grecia ${ }^{1[0000-0001-7770-}$

${ }^{1}$ Universidad Nacional de San Martín, Tarapoto, Perú acernalunsm.edu.pe

Resumen. El cogollero del maíz (Spodoptera frugiperda) es la plaga más importante de este cultivo en la región San Martín, su crianza masiva, para fines de estudiar su biología, crianza de enemigos naturales y otros, se ve limitada por la falta de insumos; por esta razón el objetivo del estudio fue evaluar los diferentes parámetros fisiológicos y biológicos de S. frugiperda, criada en una dieta artificial elaborada con insumos de la región. Se utilizó 35 larvas de primer ínstar para cada tratamiento, cada larva representó una repetición. Para el desarrollo larval, se utilizó una incubadora a $30 \pm 1{ }^{\circ} \mathrm{C}$ y fotofase 14h. Se evaluó el porcentaje de viabilidad y la duración de los diferentes ínstares, peso de pupas y deformaciones; el número de mudas se determinó midiendo la capsula cefálica de larvas; en adultos se evaluó la duración del periodo de pre-oviposición, oviposición y post-oviposición, y la fecundidad bruta. Los resultados sugieren que la dieta ESALQmodificada es la más adecuada para la crianza $S$. frugiperda, ya que mostró una viabilidad larval de 54,3\% y 5 instares, las pupas tuvieron mayor peso y los adultos presentaron mayor fecundidad (848,2 huevos por hembra); las pupas sobre la dieta con insumos de la región, presentaron deficiente quitinización de los primeros segmentos abdominales y $0 \%$ de viabilidad.

Citar como: CernaMendoza, A., Coronado, M.F., Doria-Bolaños, M. García-Gonzales, P., \& Fachin-Ruiz, G. (2021). Formulación de dieta artificial para la crianza de Spodoptera frugiperda utilizando insumos de la región de San Martín. Revista Agrotecnológica Amazónica, 1(2), 40-52. https://doi.org/10.51252/ra a.v1i2.103

Recibido: $13 / 04 / 2020$

Aceptado: 06/07/2020

Publicado: 19/07/2021
Palabras clave: Dieta artificial, harina de plátano, polvillo de arroz, $S$. frugiperda

Abstract. Fall armyworm (Spodoptera frugiperda) is the most important pest of this crop in the San Martín region. Its massive breeding, for the purpose of studying its biology, breeding of natural enemies and others, is limited by the lack of inputs; for this reason, the objective of the study was to evaluate the different physiological and biological parameters of $S$. frugiperda, raised on an artificial diet made with inputs from the region. 35 first instar larvae were used for each treatment, each larva represented a repetition. For larval development, an incubator was used at $30 \pm 1{ }^{\circ} \mathrm{C}$ and photophase 14h. The percentage of viability and the duration of the different instars, pupal weight and deformations were evaluated; the number of molts was determined by measuring the cephalic capsule of larvae; in adults the duration of the pre-oviposition, oviposition and postoviposition period, and gross fertility were evaluated. The results suggest that the ESALQ-modified diet is the most suitable for raising S. frugiperda, since it showed a larval viability of $54.3 \%$ and 5 instars, the pupae had greater weight and the adults presented higher fecundity (848.2 eggs per female); the pupae on the diet with inputs from the region, presented deficient chitinization of the first abdominal segments and $0 \%$ viability.

Keywords: Artificial diet, banana flour, rice powder, S. frugiperda 


\section{$1 \quad$ Introducción}

En la región San Martín son plagas de gran interés agrícola, el gusano cogollero (Spodoptera sp.) en arroz, maíz y otros cultivos, el barreno de los tallos (Diatraea sp.) en caña de azúcar, maíz, arroz, y otras poáceas, que deberían ser conocidas y estudiadas estableciendo módulos de crianza en ambientes adecuados.

El uso de dietas artificiales para la crianza de insectos en el país tiene escasos reportes, así podemos mencionar la crianza de lepidópteros (Spodoptera sp., y Diatraea sp.), en la costa peruana y la crianza de mosca de la fruta (Ceratitis capitata) a través del proyecto "MOSCAMED" como uno de los más importantes, por su alcance y tecnología utilizados. En tanto, hay insuficientes empresas formalizadas, que se dediquen a la crianza y/o producción y comercialización de insectos como ocurre en Europa y algunos países de la región (Brasil, Cuba, Costa Rica, etc.).

El Perú es uno de los países pioneros en américa latina donde se implementó el manejo integrado de plagas en el cultivo del algodonero y pionero en el control biológico, la crianza masal de Trichogramma spp se implementó en la década del 50, utilizando técnicas de crianza avanzados para la época y con asesoramiento de especialistas de la Universidad de CaliforniaEUA. Hasta el 2000, se han introducido al país 93 especies benéficas (la mayoría parasitoides) de las cuales se han establecido 28 , y todas ellas cuanto sus presas y/o hospederos, han sido criadas con dietas naturales y liberadas en forma inoculativa en cultivos perennes y semiperennes (Valdivieso \& Bartra, 2000).

El sistema de crianza utilizado en algunos centros de investigación (Universidades, Institutos Tecnológicos, Institutos de Investigación, empresas privadas, etc.) para proveerse de insectos en sus diferentes estadíos, es alimentándolos con "dietas naturales", con las consiguientes desventajas: indisponibilidad del alimento fresco y oportuno, sobredimensionamiento de jaulas y ambientes debido al volumen de los mismos y contaminación biológica (entomopatógenos) y química (residuos de pesticidas); pues los objetivos de tales crianzas son básicamente la investigación en biología. Así, la crianza de insectos utilizando dietas artificiales se convierte en uno de los componentes importantes de la entomología tanto básica cuanto aplicada.

Para la crianza de $S$. frugiperda, en la ESALQ-USP, Brasil viene utilizando una dieta patrón compuesta de: frejol, harina de trigo y torta de soya, agar, vitaminas, sales minerales y antibióticos, insumos escasos y costosos en nuestra región, por lo que pretendemos, como objetivo del estudio, reemplazar la harina de trigo por polvillo de arroz, y la torta de soya por harina de plátano $(50 \%)$ y harina de maíz suave $(50 \%)$, existentes en nuestra región, para la crianza de cogollero. 


\section{Materiales y Métodos}

Se utilizó equipo básico para la preparación de las dietas: cocina de 02 hornillas a gas, licuadora, batidora eléctrica, olla a presión, recipientes graduados de polietileno, pipeteador, pipetas $(10 \mathrm{ml}, 1 \mathrm{ml})$, probeta de 011 , coladores $(10 \mathrm{~cm}$ y $20 \mathrm{~cm})$, refrigeradora, cámara de vacío con luz ultravioleta y luz normal, balanza analítica de 1000 g, estufa para esterilizar, vasijas plásticas de diferentes volúmenes, incubadora, destilador de agua, congeladora mediana.

Como fuentes de carbohidratos y proteínas se empleó: frejol, germen de trigo, levadura, caseína, proteína y afrecho de soya, solución vitamínica, sales de Wesson, cloreto de colina. Los insumos regionales incorporados a la dieta artificial, fueron: frejol huasca, polvillo de arroz (subproducto del pilado de arroz), harina de plátano y harina de maíz suave. Se preparó una solución vitamínica fortificante recomendada por Parra (1996), compuesta de vitaminas diluidas en dextrosa (Tabla 1); y también se preparó la dilución de sales de Wesson.

\section{Tabla 1}

Solución vitamínica fortificante y sales Wesson, utilizada para la elaboración de dietas artificiales para insectos en la ESALQ-USP

\begin{tabular}{lrlr}
\multicolumn{2}{c}{ Vitamina } & Cantidad & \multicolumn{2}{c}{ Sal mineral } & Cantidad (\%) \\
\hline Vitamina A concentrada (200 & $4,5 \mathrm{~g}$ & Carbonato de calcio & 21,00 \\
000 unidades por gramo) & & & \\
Vitamina D concentrada (400 & $0,25 \mathrm{~g}$ & Fosfato de calcio & 14,90 \\
000 unidades por gramo) & & & \\
Alfa-tocoferol & $5,0 \mathrm{~g}$ & Sulfato de cobre $(5 \mathrm{H} 2 \mathrm{O})$ & 0,04 \\
Ácido ascórbico & $45,0 \mathrm{~g}$ & Fosfato férrico & 1,47 \\
Inositol & $5,0 \mathrm{~g}$ & Sulfato de magnesio & 9,00 \\
Cloreto de colina & $75,0 \mathrm{~g}$ & Sulfato Manganoso \\
Menadiona & $2,25 \mathrm{~g}$ & Sulfato de potasio y aluminio & 0,02 \\
Ácido p-aminobenzoico & $5,0 \mathrm{~g}$ & Cloreto de potasio & 0,009 \\
Niacina & $4,5 \mathrm{~g}$ & Iodeto de potasio & 12,00 \\
Riboblavina & $1,0 \mathrm{~g}$ & Monofosfato de potasio & 0,005 \\
Hidrocloreto de piridoxina & $1,0 \mathrm{~g}$ & Cloreto de sodio & 31,00 \\
Hidrocloreto de tiamina & $1,0 \mathrm{~g}$ & Fluoreto de sodio & 10,50 \\
Pantotenato de calcio & $3,0 \mathrm{~g}$ & 0,057 \\
Biotina & $20,0 \mathrm{mg}$ & \\
Ácido fólico & $90,0 \mathrm{mg}$ & \\
Vitamina B12 & $1,35 \mathrm{mg}$ & \\
Fuente: Tomado de Parra (1996) & &
\end{tabular}

La composición de las dietas patrón (dieta ESALQ-USP) y modificada con insumos de la región utilizadas en la presente investigación, se muestran en la Tabla 2.

\subsection{Establecimiento del módulo de crianza}

Se colectaron larvas de Spodoptera frugiperda en cultivos de maíz y caña de azúcar en distritos de Tarapoto, Morales y Banda de Shilcayo durante el periodo de marzo-diciembre 2014, para establecer el módulo de cría, los módulos fueron mantenidos con dieta natural (tallos frescos y hojas de maíz); los adultos de Spodoptera obtenidos de las colectas de campo fueron manejados 
en una caja de crianza de (45 $\mathrm{cm}$ x $70 \mathrm{~cm}$ y $33-53 \mathrm{~cm}$ de altura) (ver Figura 1), acondicionando plántulas de arroz (estadío de macollamiento) en forma de florero para obtención de posturas y refugio de adultos, no se suministró alimento adicional para adultos; las posturas fueron colectadas diariamente y acondicionadas en placas de Petri hasta la eclosión de las larvas. Las larvas de primer ínstar fueron acondicionadas en tapers de $20 \mathrm{~cm}$ x $30 \mathrm{~cm}$ con trozos de cogollo de maíz; el cambio de dieta fue interdiario.

\section{Tabla 2}

Composición de una dieta artificial (patrón) utilizada en la ESALQ-USP-BRASIL y una modificada con insumos de la región San Martín, para la crianza de Spodoptera frugiperda.

\begin{tabular}{lrlr}
\hline \multicolumn{2}{c}{ DIETA ESALQ-USP } & \multicolumn{2}{c}{ DIETA CON INSUMOS REGIONALES } \\
\hline \multicolumn{1}{c}{ Insumo } & Cantidad & \multicolumn{1}{c}{ Insumo } & Cantidad (\%) \\
\hline Frejol & $37,5 \mathrm{~g}$ & Frejol huasca & $37,5 \mathrm{~g}$ \\
Germen de trigo & $30,0 \mathrm{~g}$ & Polvillo arroz & $30,0 \mathrm{~g}$ \\
Proteína de soya* & $15,0 \mathrm{~g}$ & Harina de platano & $15,0 \mathrm{~g}$ \\
Caseína* & $15,0 \mathrm{~g}$ & Harina de maíz suave & $15,0 \mathrm{~g}$ \\
Levadura & $18,75 \mathrm{~g}$ & Levadura & $18,75 \mathrm{~g}$ \\
Solución vitamínica & $4,5 \mathrm{ml}$ & Solución vitamínica & $4,5 \mathrm{ml}$ \\
Ácido ascórbico & $1,8 \mathrm{~g}$ & Ácido ascórbico & $1,8 \mathrm{~g}$ \\
Ácido sórbico & $0,9 \mathrm{~g}$ & Ácido sórbico & $0,9 \mathrm{~g}$ \\
Nipagin (metilparahidroxi- & $1,5 \mathrm{~g}$ B & Nipagin (metilparahidroxi- & $1,5 \mathrm{~g}$ \\
benzoato) & & benzoato) & \\
Tetraciclina & $56,5 \mathrm{mg}$ & Tetraciclina & $56,5 \mathrm{mg}$ \\
Formaldehído (40\%)* & $1,8 \mathrm{ml}$ & Formaldehído (40\%)* \\
Agar & $11,5 \mathrm{~g}$ & Agar & $1,8 \mathrm{ml}$ \\
Agua destilada & $600 \mathrm{ml}$ & Agua destilada & $11,5 \mathrm{~g}$ \\
& & & $600 \mathrm{ml}$ \\
\hline
\end{tabular}

Para mantener las colonias, se utilizó como alimento natural, plantas de maíz, obtenidas de parcelas instaladas en forma secuencial (siembra mensual durante el periodo marzo 2014 marzo 2015) en el distrito de Morales (ciudad universitaria).

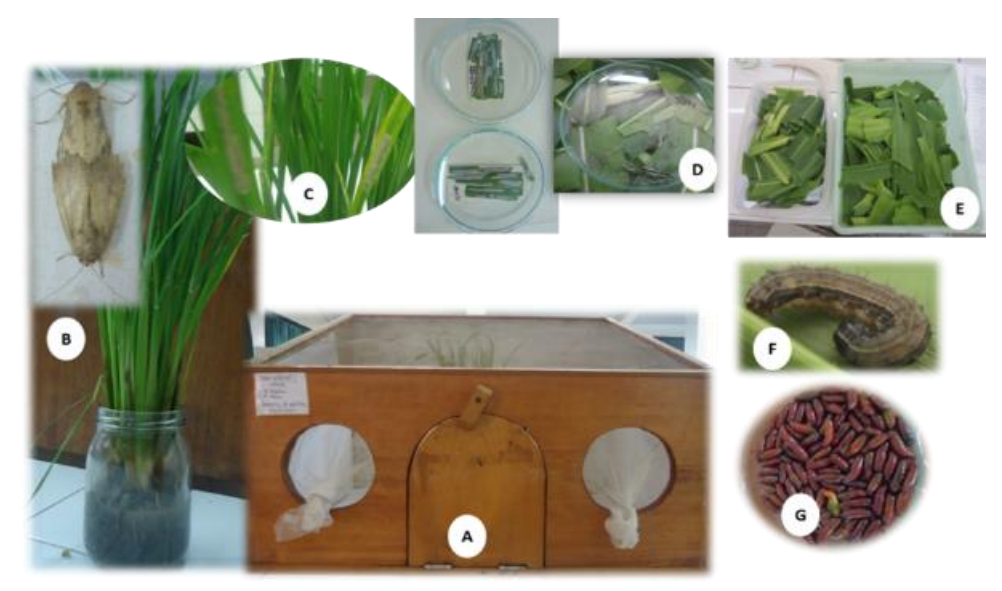

Figura 1: Secuencia de manejo del pie de cría de Spodoptera frugiperda: A. Jaula de crianza para manejo de adultos; B. Macollo de arroz utilizado como refugio y substrato de postura para adultos. C. Posturas, colecta y acondicionamiento en placas de Petri. D. Larvas recién eclosionadas; E. acondicionamiento de larvas de primer ínstar en tallos frescos de maíz utilizado como sustrato alimenticio; F y G. Larvas de cuarto ínstar y pupas listas para ser acondicionadas en la jaula. 


\subsection{Preparación de la dieta artificial}

El frejol cocinado y frío, se mezcló con los demás ingredientes (excepto el agar), se agregó agua y se batió en la licuadora. El agar fue disuelto en forma separada en agua caliente, luego los dos contenidos fueron mezclados, homogenizados con un agitador eléctrico, y transferida a los recipientes de crianza (vasos descartables de polipropileno de $30 \mathrm{ml}$ (altura $45 \mathrm{~mm}$, diámetro superior $35 \mathrm{~mm}$ y diámetro inferior $25 \mathrm{~mm}$ ). Los anticontaminantes y vitaminas fueron adicionados a la dieta cuando ésta alcanzó de $60{ }^{\circ} \mathrm{C}$ a $65^{\circ} \mathrm{C}$.

\subsection{Instalación del ensayo}

Se probaron tres dietas (tratamientos) en un DCA: T1= dieta natural (hojas y tallos tiernos de maíz); T2= dieta ESALQ-USP, Brasil modificada, compuesta de: frejol, harina de trigo, torta de soya, levadura, solución vitamínica, ácido ascórbico, ácido sórbico, nipagin, tetraciclina, agar y agua destilada; T3= dieta modificada con insumos de la región: se reemplazó la harina de trigo por polvillo de arroz, y la torta de soya por harina de plátano (50\%) y harina de maíz suave $(50 \%)$.

En cada tratamiento se instalaron 35 larvas de primer ínstar de la primera generación (F1) a 24 horas después de la eclosión, cada larva constituyó una repetición.

Después de realizar la infestación, los vasos fueron acondicionados en una incubadora a 30 1 ${ }^{\circ} \mathrm{C}$ hasta la pupación. En forma interdiaria, se midió la capsula cefálica de 15 larvas marcadas; en la dieta natural se cambió el alimento interdiario. Se realizó el sexado de pupas al momento de ser colectadas, según Butt \& Cantu (1962) citado por Silveira Garcia et al. (2014), también se evaluó las deformaciones y peso de cada una. Luego fueron acondicionadas en jaulas de madera para S. frugiperda. Se formó 05 parejas de adultos en T1 y T2 respectivamente, para evaluar longevidad y fertilidad.

Las posturas de cada hembra fueron colectadas en forma diaria, etiquetadas y se contó el número de huevos por postura (masa).

El desarrollo de larvas se mantuvo en una incubadora de 1101 marca MMM, modelo FRIOCELL 111 a temperatura constante $30^{\circ} \mathrm{C}$ y fotofase $14 \mathrm{~h}$; la emergencia de adultos, y la obtención de posturas fue a temperatura ambiente $\left(24{ }^{\circ} \mathrm{C}\right.$ a $28{ }^{\circ} \mathrm{C}$ aproximadamente), con humedad relativa del aire de $70 \% \pm 10 \%$ y fotofase de 14 horas.

\section{Resultados y discusiones}

El porcentaje de viabilidad de larvas en dietas artificiales es muy variable, y los datos reportados en diferentes experimentos inclusive para las mismas dietas varía; así, la dieta T2 (dieta ESALQ-USP) utilizada como dieta patrón en el presente experimento con 54,29\% de viabilidad, 
corresponde a la dieta reportada por Greene et al. (1976) modificada por Parra (1996) que fue probada también por Arévalo Maldonado \& Zenner de Polanía (2009) en Colombia donde obtuvieron $100 \%$ de viabilidad de larvas en la F1, 86,5\% en la F2 y 76,5 en la F3; y al igual que en el presente estudio una viabilidad de pupas del 100\%. La dieta natural (T1) que consistió de hojas y cogollos frescos de maíz, alcanzó una viabilidad larval de 71,43\%, (Tabla 3), siendo también inferior a 83,33\% reportado por Arévalo Maldonado \& Zenner de Polanía.

La dieta T3 fue inviable (viabilidad larvas 5,71\% y viabilidad de pupas 0\%). S. frugiperda, presentó alta mortalidad de larvas en el primer y último ínstar. En el último ínstar, no se produjo la muda completa, quedando parte de la exuvia adherida al cuerpo de la larva en el primer y segundo segmento abdominal (Figura 2, B y C). Sin embargo, dieta natural y ESALQ no alcanzaron sobrevivencia superior a 75\%, preconizada por Singh $(1977,1983,1985)$ como mínimo exigido para considerar a una dieta adecuada para el desarrollo de un determinado insecto.

Ambas dietas testadas, de acuerdo a su composición, pueden ser calificadas como merídicas, puesto que contienen más de un ingrediente de composición desconocida o inadecuadamente definida (Dougherty, 1959), como es el caso frejol huasca, polvillo de arroz harina de plátano y harina de maíz suave y, por tanto, constituirse en dietas inadecuadas para el desarrollo y crecimiento del cogollero del maíz, ya que una dieta nutricionalmente completa en cultivo axénico, para la mayoría de insectos debe contener todos o la mayor parte de los siguientes elementos: proteínas o aminoácidos (10 esenciales), carbohidratos, ácidos grasos, colesterol, colina, inositol, ácido pantoténico, nicotinamida, tiamina, riboflavina, ácido fólico, piridoxina, vitamina B12, caroteno o vitamina A, tocoferol, ácido ascórbico, minerales y agua (Vanderzant, 1974).

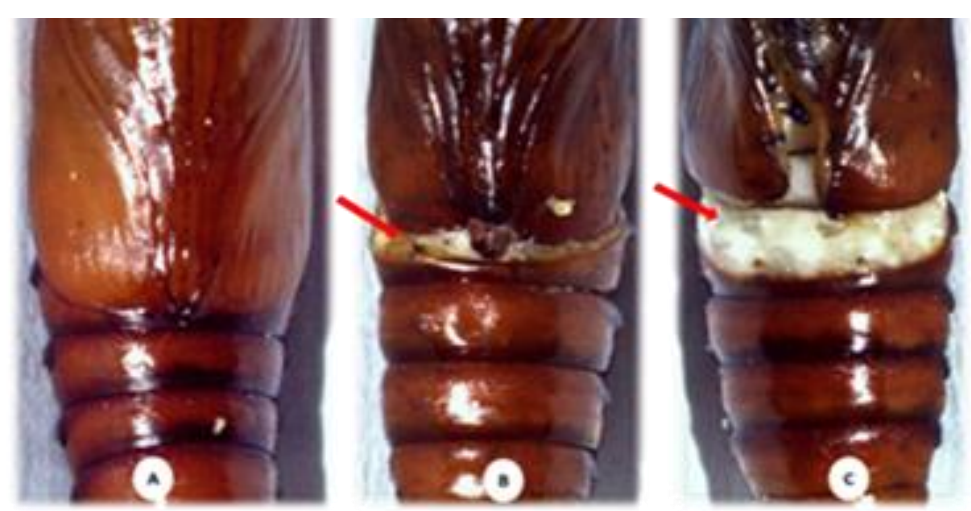

Figura 2. Pupas de Spodoptera frugiperda criadas en dos dietas artificiales: A. Pupa normal obtenida en la dieta estándar T2, utilizada en la ESALQ-USP, Brasil (compuesta de frejol, harina de trigo, torta de soya, levadura, solución vitamínica, ácido ascórbico, ácido sórbico, nipagin, tetraciclina, agar y agua destilada); B, C. Pupas con deficiente quitinización de los primeros segmentos abdominales (nótese las flechas), obtenidas en dieta modificada con insumos de la región, donde se reemplazó la harina de trigo por polvillo de arroz, y la torta de soya por harina de plátano (50\%) y harina de maíz suave (50\%) (T3). 
El peso de pupas en dieta natural (T1) y en la dieta ESALQ-USP (T2), fue de 0,147 g y 0,197 g respectivamente (Tabla 3), valores parecidos al T2, encontró Arévalo Maldonado \& Zenner de Polanía (2009) (0,16 - 0,21g). Las pupas obtenidas en T3 (dieta modificada), mostraron falta de quitinización en los primeros segmentos abdominales (deformación apreciada en la Figura 2, B y C); de algunas pupas deformes, emergieron también adultos deformes (Figura 5 D). El porcentaje de deformación fue de $100 \%$ en pupas y adultos.

S. frugiperda, presenta dimorfismo sexual en estado de pupas tal como se observa en la Figura 3 , lo que permitió formar las parejas con pupas de la misma edad para la evaluación de adultos.
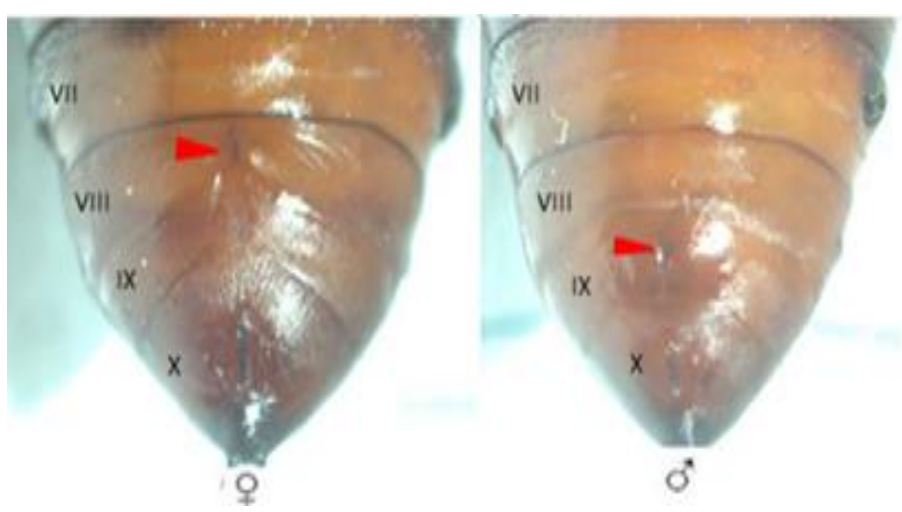

Figura 3. Dimorfismo sexual en pupas de Spodoptera frugiperda; obsérvese el orificio urogenital de las hembras en el octavo y en machos en el noveno segmento abdominal.

\subsection{Estados de desarrollo $S$. frugiperda}

La figura 4, muestra el número de estadíos para los dos primeros tratamientos (T1 y T2), el tratamiento T3, con insumos modificados no fue considerado porque presentó alta mortalidad de larvas en el primer ínstar. S. frugiperda, presentó 6 estadíos para ambos tratamientos, con una pequeña diferencia, las larvas fueron más vigorosas en la dieta artificial, como se aprecia en el gráfico, en el último estadio, el ancho de la cápsula cefálica fue mayor a 2,5 $\mathrm{mm}$, mientras que en la dieta natural fue menor a $2,5 \mathrm{~mm}$, por tanto, también dieron origen a pupas de mayor peso, como se aprecia en el Tabla 3 y a adultos más fecundos.

Tabla 3

Viabilidad de larvas y pupas (\%), peso de pupas y razón sexual para S. frugiperda criada en dieta artificial

\begin{tabular}{|c|c|c|c|c|c|c|c|c|}
\hline \multirow{2}{*}{ Tratamientos* } & \multirow{2}{*}{$\begin{array}{c}\mathbf{N}^{\circ} \\
\text { larvas } \\
\text { infesta- } \\
\text { das }\end{array}$} & \multicolumn{2}{|c|}{$\begin{array}{c}\begin{array}{c}\text { Viabilidad larvas } \\
(\%)\end{array} \\
\end{array}$} & \multirow{2}{*}{$\begin{array}{l}\text { Viabilidad } \\
\text { pupas }(\%)\end{array}$} & \multirow{2}{*}{$\begin{array}{c}\text { Peso } \\
\text { pupas } \\
(\mathrm{g})\end{array}$} & \multicolumn{2}{|c|}{ Relación sexual } & \multirow{2}{*}{$\begin{array}{l}\text { Propor- } \\
\text { ción }\end{array}$} \\
\hline & & $\mathbf{N}^{\circ}$ & $\%$ & & & $\begin{array}{l}\text { Hem- } \\
\text { bras }\end{array}$ & $\begin{array}{l}\text { Ma- } \\
\text { chos }\end{array}$ & \\
\hline T1: Dieta natural & 35 & 25 & 71,43 & 100,00 & 0,147 & 16 & 9 & 0,64 \\
\hline $\begin{array}{l}\text { T2: Dieta } \\
\text { ESALQ }\end{array}$ & 35 & 19 & 54,29 & 100,00 & 0,197 & 12 & 7 & 0,63 \\
\hline $\begin{array}{l}\text { T3: Dieta modi- } \\
\text { ficada }\end{array}$ & 35 & 2 & 8,71 & 0,00 & 0.165 & 2 & 0 & \\
\hline
\end{tabular}




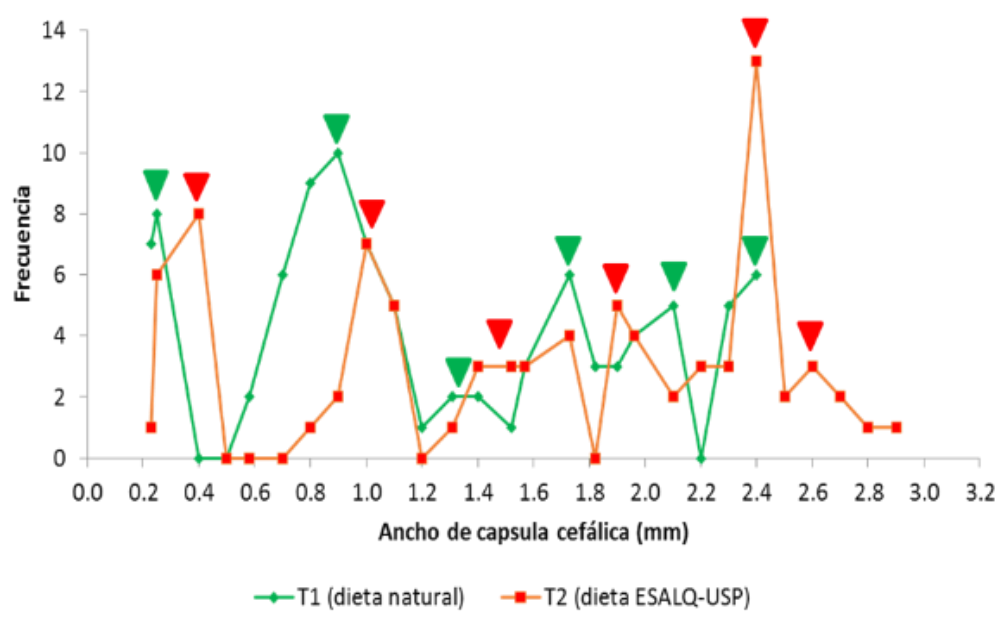

Figura 4. Distribución de frecuencia del ancho de capsula cefálica de Spodoptera frugiperda desarrollada en dieta natural (T1) y en la dieta artificial utilizada en la ESALQ-USP, Brasil (compuesta de frejol, harina de trigo, torta de soya, levadura, solución vitamínica, ácido ascórbico, ácido sórbico, nipagin, tetraciclina, agar y agua destilada) (T2). Las zetas, indican el número de mudas (i1=instar 1; i2=instar 2; i3=instar 3; i4=instar 4; i5=instar 5; i6=instar 6).

En la dieta modificada (T3) con insumos de la región, se observó un alargamiento de la fase larval, y alta mortalidad en los estadios 4 y 5 (Figura 5, B y C).

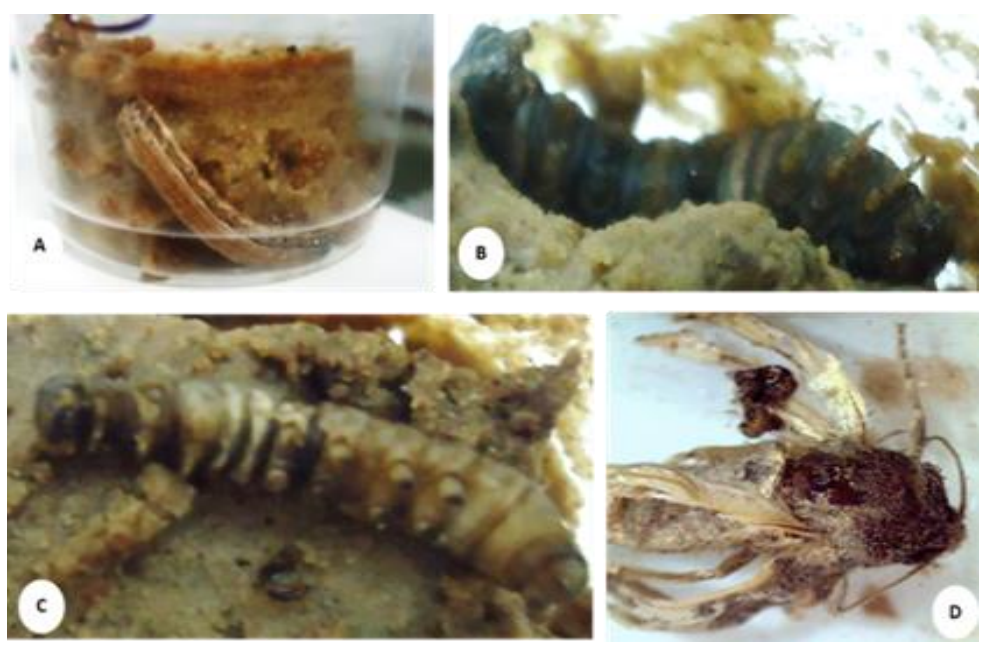

Figura 5. Efecto de la dieta artificial modificada con insumos de la región, donde se reemplazó la harina de trigo por polvillo de arroz, y la torta de soya por harina de plátano (50\%) y harina de maíz suave $(50 \%)$ sobre Spodoptera frugiperda: A. Larva con desarrollo normal, obtenida en la dieta estándar utilizada en la ESALQ-USP, Brasil (compuesta de frejol, harina de trigo, torta de soya, levadura, solución vitamínica, ácido ascórbico, ácido sórbico, nipagin, tetraciclina, agar y agua destilada); B,C. Larvas de último estadio y pre-pupa muertas; D. Adulto emergido con deformaciones.

Villa Castoreña \& Catalán Valencia (2004) al determinar el número de estadios de esta misma especie criada con hojas y tallos de maíz, encontraron un máximo de 5 estadios, y un ancho cefálico promedio para el quinto ínstar de 2,77 mm; mientras que Arévalo Maldonado \& Zenner de Polanía (2009) encontraron en promedio de seis a ocho estadíos utilizando la misma dieta 
ESALQ. Por otra parte, Murúa et al. (2003) obtuvieron hasta 10 en una dieta a base de arroz, fécula de maíz y germen de trigo. Frente a ello, Kester \& Smith (1984) mencionan que la nutrición en los insectos influye en la duración de los diferentes estadíos (número y tiempo), mortalidad y desempeño reproductivo (fecundidad).

\subsection{Fase de adultos}

La duración del ciclo biológico de $S$. frugiperda se muestra en la Tabla 4, en la dieta natural (T1) y en la dieta artificial ESALQ-USP (T2), fue de 36,74 y 38,56 días respectivamente, sin diferencia para la fase de huevo y pupa, en dieta natural, las fases de larva y preoviposición, fue menor mientras que las fases de oviposición y post oviposición fueron mayores que en la dieta ESALQ. Los valores son análogos a los encontrados por Arévalo Maldonado \& Zenner de Polanía (2009).

Tabla 4

Estados de desarrollo y duración (días) de S. frugiperda criada en dos dietas artificiales

\begin{tabular}{|c|c|c|c|c|c|c|c|}
\hline \multirow[b]{2}{*}{$\begin{array}{c}\text { Trata- } \\
\text { mientos* }\end{array}$} & \multicolumn{6}{|c|}{ Estados de desarrollo y duración (días)** } & \multirow[b]{2}{*}{ Total } \\
\hline & Huevo & Larva & Pupa & $\begin{array}{l}\text { Pre ovipo- } \\
\text { sición }\end{array}$ & $\begin{array}{l}\text { Oviposi- } \\
\text { ción }\end{array}$ & $\begin{array}{l}\text { Post ovipo- } \\
\text { sición }\end{array}$ & \\
\hline $\mathrm{T} 1$ & $2,17 \pm 0,15$ & $20,32 \pm 0,48$ & $4,05 \pm 0,39$ & $5,60 \pm 1,52$ & $3,80 \pm 1,79$ & $0,80 \pm 0,45$ & 36,74 \\
\hline $\mathrm{T} 2$ & $2,33 \pm 0,06$ & $22,37 \pm 0,50$ & $4,26 \pm 0,26$ & $4,40 \pm 0,55$ & $4,20 \pm 1,30$ & $1,00 \pm 0,00$ & 38,56 \\
\hline T3 & $\mathrm{x}$ & 30 & $\mathrm{x}$ & $\mathrm{x}$ & $\mathrm{x}$ & $\mathrm{x}$ & $\mathrm{x}$ \\
\hline
\end{tabular}

Como se mencionó para los estadios de larvas y pupas, la mortalidad del T3 fué alto, los adultos murieron al momento de la emergéncia o recién emergidos, en tanto también se observó mortalidad de parejas copulando en el tratamiento T2.

La fecundidad bruta (Mx) para hembras criadas en dieta natural (T1) y en la dieta artificial ESLAQ-USP (T2) fué de 388,4 y 848,2 huevos por hembra respectivamente (Figura 6), valores parecidos a los reportados por Arévalo Maldonado \& Zenner de Polanía (2009) en las mismas dietas con 743 y 905,8 huevos por hembra respectivamente.

Producir insectos de calidad, es el objetivo final de los laboratorios destinados a éste fin; la calidad de insectos dependiendo del objetivo de las crianzas debe ser monitoreado permanentemente, en Europa por ejemplo, para las crianzas masales con fines de control biológico existe una serie de normas padronizadas, desarrolladas en alianza con la Organización Internacional de Control Biológico (IOBC) y empresarios de biocontrol para testes de calidad en crianzas de diversos enemigos naturales utilizados en cultivos protegidos.

Así, la calidad está relacionada con la razón sexual, fecundidad, longevidad, predación, tamaño de adulto, actividad de vuelo y desempeño en campo (van Lenteren, 1993). El peso de adultos, 
está a su vez relacionado directamente con el peso de las pupas al día siguiente de su formación (Bustillo, 2019).

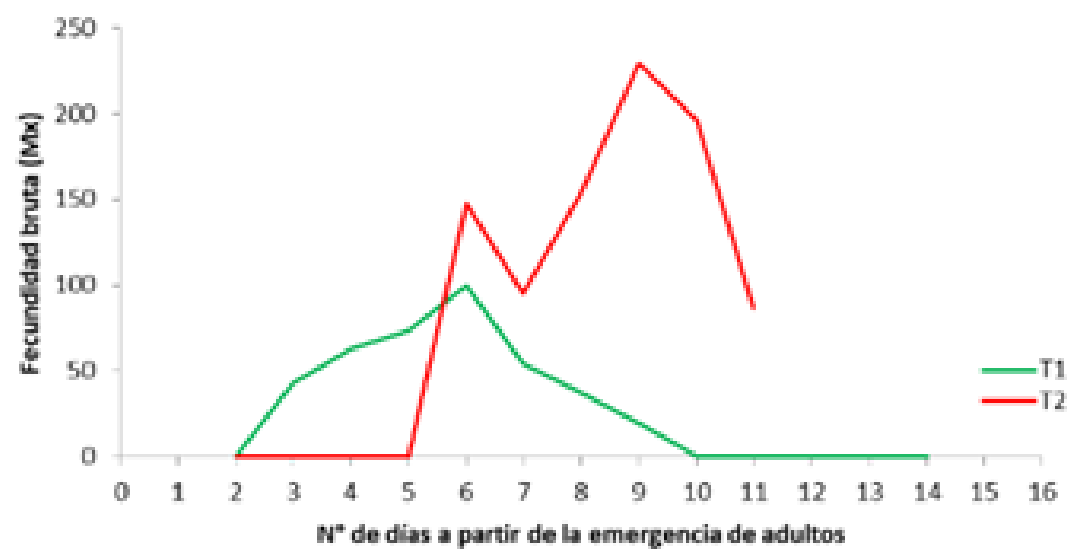

Figura 6. Fecundidad bruta para Spodoptera frugiperda desarrollada en dieta natural (T1) y en la dieta artificial utilizada en la ESALQ-USP, Brasil (compuesta de frejol, harina de trigo, torta de soya, levadura, solución vitamínica, ácido ascórbico, ácido sórbico, nipagin, tetraciclina, agar y agua destilada) (T2).

S. frugiperda, es un lepidóptero cuyo imago puede vivir en promedio de 7 a 8 días, sobreviviendo en éste estado de los nutrientes almacenados en sus tejidos gordurosos; tal como afirma Chapman (1982) que es bastante evidente en adultos de Lepidoptera que no se alimentan. En estos casos los procesos metabólicos del adulto dependen de las reservas de los estadios inmaduros. Larvas de Anthonomus grandis (Coleoptera) almacenan colina e inositol suficientes para permitir el desarrollo del huevo, mismo si estos nutrientes fuesen excluidos de la dieta del adulto.

Según la bibliografía consultada, para la cría experimental de $S$. frugiperda se emplea diversidad de dietas artificiales; la mayor parte de estas son elaboradas teniendo como base harinas de frejol, soja, maíz, alfalfa, germen de trigo, entre otros, adicionadas con distintos complejos vitamínicos e importantes cantidades de agar de alta pureza y de elevado costo (Burton, 1969; Burton \& Perkins, 1989; Perkins, 1979; Singh, 1985; Valverde et al., 1995).

\section{Conclusiones}

La dieta artificial T2, utilizada en la ESALQ-USP, Brasil, compuesta de frejol, harina de trigo, torta de soya, levadura, solución vitamínica, ácido ascórbico, ácido sórbico, nipagin, tetraciclina, agar y agua destilada, fue adecuada para el desarrollo de S. frugiperda. Esto permitió su desarrollo larval, con una viabilidad y duración semejante a la dieta natural. Los adultos, tuvieron una fecundidad igual al doble de aquellos provenientes de dieta natural y, además, fueron ligeramente más grandes y vigorosos; del mismo modo, las larvas presentaron 
mayor tamaño de capsula cefálica y las pupas tuvieron mayor peso promedio que aquellas provenientes de dieta natural.

La dieta modificada (T3) con insumos de la región, prolongó el ciclo larval de S. frugiperda y presentó alta mortalidad para el primer y último instar larval, y las pupas presentaron deficiente quitinización de los primeros segmentos abdominales, malformación que conllevó a la muerte de las mismas y algunos adultos que consiguieron emerger, presentaron deformaciones (alas principalmente) y murieron a pocas horas de la emergencia.

\section{Agradecimientos}

Los autores agradecen al Instituto de Investigación y Desarrollo de la Universidad Nacional de la San Martín (UNSM-T) por el financiamiento y acompañamiento de la ejecución de la investigación.

Al laboratorio de Entomología de la Facultad de Ciencias Agrarias, por brindar la infraestructura y todas las facilidades para la ejecución del presente trabajo.

\section{Referencias bibliográficas}

Arévalo Maldonado, H., \& Zenner de Polanía, I. (2009). Evaluación de dietas merídicas para la cría en laboratorio de Spodoptera frugiperda (J.E. Smith) (Lepidoptera: Noctuidae).

Revista U.D.C.A Actualidad \& Divulgación Científica, 12(1).

https://doi.org/10.31910/rudca.v12.n1.2009.644

Burton, R. L. (1969). Mass rearing the corn earworm in the laboratory (pp. 7-8).

Burton, R. L., \& Perkins, W. D. (1989). Rearing the corn earworm and fall armyworm for maize resistance studies. Toward insect resistant maize for the third world, Centro Internacional de Mejoramiento de Maiz y Trigo, Mexico, DF, 37-45.

Bustillo, A. (2019). La nutrición en insectos. Sociedad Colombiana de Entomología. Medellín. Boletín de Divulgación.

Butt, B. A., \& Cantu, E. (1962). Sex determination of lepidopterous pupae. En Agricultural Research Service, U.S. Dept. of Agriculture.

Chapman, R. F. (1982). The Insects: Structure and Function (Tercera).

Dougherty, E. C. (1959). Introduction to axenic culture of invertebrate metazoa: a goal. Annals of the New York Academy of Sciences, 77(2), 27-54. https://doi.org/10.1111/j.17496632.1959.tb36891.x

Greene, G. L., Leppla, N. C., \& Dickerson, W. A. (1976). Velvetbean Caterpillar: A Rearing Procedure and Artificial Medium123. Journal of Economic Entomology, 69(4), 487-488. https://doi.org/10.1093/jee/69.4.487

Kester, K. M., \& Smith, C. M. (1984). Effects of diet on growth, fecundity and duration of 
tethered flight of Nezara viridula. Entomologia Experimentalis et Applicata, 35(1), 75-81. https://doi.org/10.1111/j.1570-7458.1984.tb03363.x

Murúa, M. G., Defagóm Víctor Hugo, \& Virla, E. G. (2003). Evaluación de cuatro dietas artificiales para la cría de Spodoptera frugiperda (Lep.: Noctuidae) destinada a mantener poblaciones experimentales de himenópteros parasitoides. Boletín de Sanidad Vegetal. Plagas, 29(1), 43-51. https://ri.conicet.gov.ar/handle/11336/52530

Parra, J. R. P. (1996). Técnicas de criação de insetos para programas de controle biológico. Piracicaba, SP: Escola Superior de Agricultura Luiz de Queiroz/Fundação de Estudos Luiz de Queiroz, Universidade de São Paulo. 134 p.

Perkins, W. D. (1979). Laboratory Rearing of the Fall Armyworm. The Florida Entomologist, 62(2), 87-91. https://doi.org/10.2307/3494084

Silveira Garcia, M., Rossato Busato, G., Pinheiro Giolo, F., Manzoni, C., Bernardi, O., Zart, M., $\&$ Medeiros Nunes, A. (2014). Tabela de vida de fertilidade de helicoverpa zea (boddie, 1850) (lepidoptera: noctuidae) em duas dietas artificiais. Current Agricultural Science and Technology, 12(1), 51-55. https://doi.org/10.18539/cast.v12i1.4469

Singh, P. (1977). Artificial Diets for Insects, Mites, and Spiders $\mid$ Pritam Singh $\mid$ Springer.

Springer US. https://www.springer.com/gp/book/9781468483512

Singh, P. (1983). A general purpose laboratory diet mixture for rearing insects. International Journal of Tropical Insect Science, 4(04), 357-362.

https://doi.org/10.1017/S1742758400002393

Singh, P. (1985). Multiple species rearing diets. En Handbook of Insect Rearing 1 (pp. 19-44). Valdivieso, L. W., \& Bartra, C. E. (2000). Control biológico en el Perú (RAAA (ed.)). Valverde, L., de Toledo, Z. A., \& Popich, S. (1995). Ciclo biológico de Spodoptera frugiperda (J:E: Smith) (Lepidoptera: Noctuidae). Acta Zoológica Lilloana, 43(1), 131-143.

van Lenteren, J. C. (1993). Quality control for natural enemies used in greenhouses.

Organisation Internationale de Lutte Biologique et Integree contre les Animaux et les Plantes Nuisibles, 89-92. https://agris.fao.org/agrissearch/search.do?recordID=FR9304542

Vanderzant, E. S. (1974). Development, Significance, and Application of Artificial Diets for Insects. Annual Review of Entomology, 19(1), 139-160.

https://doi.org/10.1146/annurev.en.19.010174.001035

Villa Castoreña, M. M., \& Catalán Valencia, E. A. (2004). Determinación de estadios larvales de Spodoptera frugiperda (J. E. Smith) (Lepidoptera: Noctuidae) para la construcción de un modelo de predicción. Folia Entomológica Mexicana, 43(3), 307-312.

https://www.redalyc.org/pdf/424/42443306.pdf 


\section{Conflicto de intereses}

Los autores declaramos que no existen conflictos de interés.

\section{Contribuciones de los autores}

Cerna-Mendoza, Agustín: Coordinación del proyecto y experimentación.

Coronado, Manuel F. y Doria-Bolaños, Manuel: Redacción y parte metodológica.

García-Gonzales, Patricia y Fachin-Ruiz, Grecia: Análisis estadístico e interpretación. 